\title{
Theory summary on price discovery function of futures market
}

\author{
NIU Ying-jie, LIANG Zhao-hui \\ (School of Economics, Tianjin Polytechnic University, Tianjin 300387, China)
}

\begin{abstract}
Price discovery is the basic function of futures market, and whether the futures market has the function of price discovery is an important research field for scholars both at home and abroad. This paper classifies the test methods and models on a basis of previous research, and introduces the applicable premise of research methods and models as well as the major research achievements of scholars at home and abroad, and also reviews the shortcomings of test methods and models.
\end{abstract}

Key words: futures price; spot price; price discovery

As the basic function of the futures market, price discovery can form fair price in the market, regulate supply and demand of the market, slow down the price fluctuation and avoid the commercial risk brought by the price fluctuation so as to lock the cost of production for the purpose of stable production profit. Therefore, the research on price discovery of futures market has never stopped since the futures contract was formally launched in 1860 .

On the empirical aspect, there exist three types of testing methods concluded from a large number of documents to inspect whether the futures market has the function of price discovery. The first one is the simple linear regression test (including the method of least squares (OLS) test and G-S model test), the second one is Engel-Granger co-integration (two-step test), and the third one is Johansen (Johansen, 1998) based on maximum likelihood estimation of co-integration test. In addition, there exist some other testing methods which differ from the above methods and models. The paper will describe these different test methods and models, make simple comment on advantages and disadvantages, and finally the authors will review the major research achievements of scholars both at home and abroad.

\section{Simple linear regression test}

\subsection{Method of least squares (OLS) test}

Before the advent of Engel-Granger two-step test, inspection of price discovery in the futures market is mainly based on the method of least squares test, which assumes that the price of two sequences, the spot price and the futures price, can meet the classical hypothesis by regression analysis at the same time.

In 1983, Bigman and others firstly proposed the testing model of the simple effectiveness of futures market that is, using the spot price on delivery day to regress futures price at a fixed time distant from the delivery day, and if futures market has the function of price discovery, then the futures price should be the immediate response of all information at present. Under the assumption of rational expectations, the regression coefficient should be $a>0, b=1$. Bigman, Goldfarb and Schechtman (1983) made an empirical test for the price discovery of futures

NIU Ying-jie, graduate student, School of Economics, Tianjin Polytechnic University; research field: financial engineering.

LIANG Zhao-hui, Ph.D., associate professor, School of Economics, Tianjin Polytechnic University; research field: financial engineering. 
price on soy, wheat and maize at Chicago Board of Trade by taking advantage of this model. They analyzed the data of futures price and spot market price from January 1975 to September 1980, and made a simple regression for the futures prices few weeks ago by using the spot market prices on delivery day. Results indicate that the futures price is not the effective estimation corresponding to the spot price on maturity day, namely, the futures price does not have the function of price discovery.

However, with the different opinions, Maberly (1985) considered that the inspection result of futures price could not imply that futures price doesn't have the function of price discovery, and he indicated that such phenomenon was caused by the application of deleting sample date of ordinary least squares regression. Elam and Dixon (1988) considered that the date of futures price and spot price is nonstationary. Therefore, there exists error on $F$ statistic of traditional test, which was no longer applied.

\subsection{Method of G-S model test}

This approach assumes that it is stationary that futures price and spot price can meet the price time series. Garbade and Silber (1983) made the earliest empirical investigation on spot market prices which are guided by futures price. They made the inspection on effect of basis change during the previous period on futures price and spot price after the period to describe the function of futures price and spot price in price discovery. As a result, it was named as G-S model. They made the investigation on seven futures varieties, including wheat, corn, oats, orange juice, copper, gold, silver and so on, and found that futures market shows the function of price discovery. Shen and Wang (1990) pointed out that if the price series was nonstationary, then it was non-efficient for testing unbiasedness by using the traditional method. By taking advantage of G-S model test, Schwarz and Szakmarytlsl (1994) inspected the price discovery of crude oil, heating oil and lead-free petrol. Moosal (2002) inspected on crude oil futures, all of which showed that futures market has the function of price discovery.

The above two kinds of test methods also have limitations. The inspection and analysis only can be carried out under the condition that the price time series of futures price and spot price can meet the classical hypothesis of regression analysis or the price time series of these two are stable. However, the futures price and spot price in the actual futures and spot markets might not meet the above two conditions. In most cases, the spot price and futures price are incompatible with the classical hypothesis of regression analysis and the price series are not stable. Therefore, these two methods cannot be applied when classical hypothesis of regression analysis cannot be met or the price series are not stable.

\section{Method of Engel-Granger two-step test}

The concept of co-integration and E-G two-step test, which are proposed and established by Engle and Granger (1987), basically solved nonstationary problem existing in price series. The theory of co-integration is mainly used in the research on the existence of long-term equilibrium relationship between these variables, which is essential for establishing econometric model with nonstationary variables and inspecting long-term equilibrium relationship between the variables. If two variables, which have their own long-term fluctuations, are cointegrated, then there exists long-term equilibrium relationship between them; Otherwise, such relationship does not exist. This is the significance of variable co-integration analysis. The establishment of inspection of variable co-integration model adopt E-G two steps, the first step is to make the unit root test and the second one is to make the co-integration test.

A group of people including Lai (1991), Fortenber, Zapata (1997) and Haigh (2000) had made an empirical 
test for relationship between the futures price and spot price by using the co-integration analysis, and the results showed that relationship of co-integration exists among most futures price and spot price, but among some of futures varieties, such relationship didn’t exist. Based on monthly data, Quan (1992) made the inspection for the lead-lag relationship between petroleum futures market price and spot market price by Granger causality judgments, and he also analyzed the dynamic relationship between the futures price and spot price by error correction model, and finally, it turns out that the spot market price was ahead of the futures market price. WU Chong-feng, WANG Hai-cheng and XING Yun (1997) made analysis on copper futures price in Shanghai and Shenzhen metal exchange by taking advantage of co-integration and Granger causality, and the result showed that among copper futures markets there exists co-integration relationship. HUA Ren-hai, ZHONG Wei-jun (2002) made the test for contract copper and aluminum by adopting the daily data from January 2, 1997 to June 29, 2001. The standard test method of causality was adopted, and the test results indicated that there existed an obvious two-way causal relationship between the copper futures price and spot price, but there only existed one-way causal relationship between the aluminum futures price and spot price. GAO Hui (2003) took the soybean of Dalian Commodity Exchange as the research object, and found that there exists co-integration between futures price and spot price. The futures price in previous stage had no guide relationship with the current spot price, and the spot price in previous stage also had no such relationship with current futures price. However, there existed immediate two-way price guide relationship between them, taking the futures copper of Shanghai futures market as the example.

ZHANG Cheng-long (2006) made an empirical analysis on relationship between the futures price and spot price by theory of co-integration and error correction model. Finally, he found that there existed long-term stable relationships between the natural logarithm of futures prices and spot price of the copper products.GENG Guo-guang and LIU Yi-qing (2007) made an empirical test in China's natural rubber futures market according to E-G Co-integration two-step test method, and the results showed that there didn't exist obvious co-integration relationship between rubber futures market price and the spot market price of the Chinese natural rubber. Therefore, it proved that the function of price discovery was not available in China's current natural rubber futures market. With the aid of unit root test, co-integration, error correction model and Granger causality, TONG Meng-hua and YANG Zhu-xin (2008), took the copper and aluminum of Shanghai futures market as examples to make empirical analyses, and the results revealed that long-term equilibrium relationship existed between the futures price and spot price about these two products, and futures price made interaction with the spot price and reinforced by each other.

Although simple and effective in the empirical analysis, single equation co-integration and E-G two-step text method are mostly appropriate for limited sample size and co-integration system or two-dimensional co-integration system which exist the only co-integration relationship. It is inappropriate for testing and estimating the large sample size and multiple co-integration relationships. When the number of dimensions of co-integration system or rank of co-integration increase, E-G two-step test will be useless. In addition, the other limitation of this approach lies in the lack of strict inference to the parameters, as the inference of the parameters is the focus of unbiased test of futures price.

\section{Method of Johansen co-integration test}

Different from methods of Engle and Grange, based on the vector ECM of co-integration system, Johansen (1988, 1991), Johansen and Juselius (1990) discussed the maximum likelihood of the long-term linear equilibrium relationship estimation within the co-integration system, and derived the statistical inference tool of co-integration 
test and parametric test using the method of the maximum likelihood to inspect market efficiency and the price discovery of futures market, which achieved good results. Such kind of test overcamed the disadvantages of E-G two-step method in the circumstances of a large sample size and multiple co-integration relationships.

H. Holly Wang and Ke Bingfan (2002) inspected the relationship between three spot market prices including wholesale prices in Tianjin and Zhengzhou as well as national average wholesale price and the corresponding futures price (week price) within the period from January 1998 to March 2002 using the method of Johansen co-integration test, and the results indicated that futures market of the wheat is inefficient and there exists long-term equilibrium relationship between futures price and spot price for the hard wheat. HUA Ren-hai and CHEN Bai-zhu (2004) made the empirical research on futures price links of copper, aluminum, soybeans and wheat in domestic futures trading market using the methods of Johansen co-integration test, error correction model and Granger causality test as well as impact response analysis, and the results showed that long-term equilibrium relationship existed in futures price of copper and aluminum on Shanghai futures exchange and co-integration relationship existed in the futures prices of soybean on Dalian Commodity Exchange and such kind of relationship didn't exist in wheat futures price on Zhengzhou Commodity Exchange. Taking the Dalian Commodity Exchange soybean, the Zhengzhou Commodity Exchange wheat and the Shanghai Futures Exchange copper as the sample. ZHU He-liang (2006) made the empirical research by using the methods of Johansen co-integration test, error correction model analysis and Granger causality test. Finally, the results indicated that there basically existed long-term equilibrium relationship between China's domestic futures price and spot price. With the help of Johansen co-integration test, information sharing model and volatility spillover effects model, LIU Qing-fu and ZHONG Wei-jun (2007) carried out multi-level empirical research, and the results showed that there existed long-term equilibrium relationship and bi-directional relationship between futures prices and spot price of copper and aluminum, and such relationships interacted and affected each other. Both futures market and spot market play important roles of price discovery, but the futures market plays the leading role in price discovery.

\section{Other testing methods}

Although the above methods play the leading role in inspecting the function of price discovery in futures markets, a number of scholars at home and abroad have also made the inspection research on price discovery of different varieties in futures market by using other methods and models which are distinct from the above ones, and they have got some results in certain extent.

Using the non-linear error correction model, Victor (1996) and other scholars took the time-varying volatility in consideration and made the inspection on relationship between the spot price and futures price of gasoline and heating oil. They found that the futures market has the function of price discovery. Through the serial correlation test and runs test, XU Jian-gang (1995) inspected the correlation of futures price changes on green bean, soybean and corn. The test results showed that the correlation of futures price changes on green bean existed obviously, the correlation of futures price changes on corn existed, and such correlation didn't exist for soybean.

With the methods of co-polymerization and market linkage index, WU La-ping (1999) made a study on integration of wheat, corn and the pig acquisition market. The results indicated that long-term integration relationship better exists between the acquisition markets of wheat and corn, and short-term market integration does not exist. With the aid of information-sharing model and volatility spillover effects model, LIU Qing-fu and WANG Hai-min (2006) made an multi-level empirical study on futures market price and the spot market price of 
the soybean and wheat in China, and they made a quantitative description for the role of spot market and futures market in the period discovery, meanwhile, they made in-depth description for the dynamic relationship between the futures and the spot market of the agricultural products. The study concluded that both futures and spot market all play important roles in price discovery, and futures markets plays the leading role, meanwhile, the bi-directional volatility spillover relationship exists between the futures market and the spot market.

\section{Summary}

By comparing the literature, researchers have relatively large differences in model selection and testing methods for inspecting the price discovery. Co-integration method, proposed by Engel and Granger in 1987, can be the division boundary in the broad. The research on price discovery was primarily based on ordinary least squares (OLS) or the GS model-based analysis before. However, this method is only applicable when two series of spot price and futures price can satisfy the classic assumption of regression analysis at the same time or price series are stationary. Generally, it is the inspection on smoothness of time series and the problem of false correlation produced by smoothness inspection. Characterized by simple, two-step test method (namely E-G two-step method), proposed by Engle and Grange, has good inspection results for small sample and the single co-integration relationship, but it can do nothing for large sample or multiple co-integration relationships. Moreover, this method requires the exogenous assumption, but cannot get more information from the test results. Co-integration testing method, proposed by Johansen, can avoid these shortcomings, so the co-integration test method on co-integration relationship is widely used. Facts have proved that using Johansen test also could achieve good inspection results.

\section{References:}

Elam, E., \& Dixon B. L.. ( 1988). Examining the validity of a test of futures market efficiency. The Journal of Futures Markets, 8(3), 365-372.

GAO Hui. (2003). An empirical analysis on the cointegration and casual relation of commodity futures price in Dalian. Journal of Taiyuan University of Technology (Social Sciences Edition), 1.

Garbade, K., \& Silber, W.. (1983). Price movements and cash discovery in futures and cash markets. Review of Economics and Statistics, 65.

GONG Guo-guang \& LIU Yi-qing. (2007). Study on price discovery function of Chinese natural rubber futures markets. Journal of Wuhan University of Technology (Information \& Management Engineering), 6.

H. Holly, Wang \& Bingfan, Ke. (2002). Efficiency tests of agricultural commodity futures markets in China. (Working paper research June 4, Washington State University).

Haigh, M.. (2000). Cointegration, unbiased expectations and forecasting in the BIFFEX freight futures market. Journal of Futures Markets, 20, 545-571.

HUA Ren-hai \& CHEN Bai-zhu. (2004). Long memory in returns and volatility in China futures market. Journal of Finance, 2.

Johansen, S. \& Juselius, K.. (1990). Maximum likelihood estimation and inference on cointegration-With applications to the demand for money. Oxford Bulletin of Economics and Statistics, 52, 169-210.

Lai, K., \& Lai M., A.. (1991). Cointegration test for market efficiency. Journal of Futures Markets, 11, 567-575.

LIU Qing-fu, ZHONG Wei-jun. (2007). Price discovery and volatility spillovers in China's metal spot-futures markets. Journal of Southeast University(Philosophy and Social Science), 9(3).

Maberly. (1985). Testing futures market efficiency: A restatement. The Journal of Futures Markets, 5, 365-372.

Quan, J.. (1992). Two-step testing procedure for price discovery role of futures prices. The Journal of Futures Markets, 12, $139-149$.

Schwarz, T. \& A. Szakmary. (1994). Price discovery in petroleum markets: Price discovery, cointegration and the time interval of analysis. Journal of Futures Markets, 9, 147-167.

SHEN, C. H. \& WANG, L. R.. (1990). Examining the validity of a test of futures market efficiency. Journal of Futures Markets, 10, 195-196.

WU Chong-feng, WANG Cai-cheng \& XING Yun. (1997). Futures prices lead relationship, cointegration and empirical analysis. Systems Enging-theory Methodology Application, 6(2).

(Edited by Ruby and Chris) 